\section{Celltech and MRC}

SIR - The House of Commons Select Committee's remarks (Nature 5 August, p.505) on Celltech's links with the Medical Research Council (MRC) raise some important issues:

(i) The cost of developing a discovery and bringing it to the market often makes a degree of monopoly essential if it is to be worthwhile for anyone to take on the development risk. On the other hand, giving one body monopoly rights for all inventions for all time may lead to stultification. So a good balance between exclusivity and competition needs to be struck.

(ii) Industry and academia quite rightly differ in their aims and ways of doing things, so collaboration between them will not be productive unless mutual understanding about aims and methods reaches a high enough level. This probably requires individuals and organizations to work together quite closely over a period of time.

The agreement between Celltech and MRC gives Celltech only a first option - MRC must always be satisfied with the commercial plans. It has other features novel in the United Kingdom which bring MRC and Celltech scientists closer together. Experimentation with a variety of frameworks for industrial/ academic collaboration is highly desirable and that between MRC and Celltech may turn out to be worth copying. It has been operating for less than two years but has already led to commercial success, for example, in antiinterferon. The time is perhaps too short to have tested the ideas fully but if a review at this stage could be helpful to others, I would be happy to see it.

G.H. FAIRTLOUGH

Chief Executive,

Celltech Limited,

Slough, Bucks, UK

\section{The numbers game}

SIR - Dr H. H. Rossi (Nature 22 July, p.320) makes a plea for a modification of our way of writing quantities in the SI system.

This raises various issues. The numbers we write in English speaking countries as 1.234 and 1,234 tend to be written the other way round in continental Europe (with a "decimal comma" instead of a decimal point, and a dot for thousands). This is a dangerous confusion, and one has to be thankful that so far it hasn't resulted in catastrophe. What makes it worse is that especially in handwriting (and sometimes also in print) not only may dots and commas be difficult to distinguish reliably, but also they may be so faint as to escape notice altogether.

What is wanted is a good clear symbol for the decimal point, which ideally should be already present on all ordinary typewriters, and not already used as a symbol for a unit of measurement or easily confused in handwriting with such a symbol.

About the only symbols satisfying all these conditions are " $\&$ " and the letter " $u$ ". If we wrote " $2 \& 34$ " or " 2 u34" for " 2.34 " there would be little danger of confusion. There is also a lot to be said for the admirable brevity of the occasional continental habit of writing, say, $2.34 \mathrm{~m}$ as " $2 \mathrm{~m} 34$ ". It is quicker to write and to say, and is unambiguous. Brevity is a great help to clarity. Although " 0.700 ”' means exactly the same as ".7", it is ".7" which makes the quickest and strongest impression on the mind.

For representing numbers in so-called scientific notation, I would suggest that we write, for example, $2(6) 34$ for $2.34 \times 10^{6}$. This notation is brief and more flexible than the traditional one. There is no objection to writing 1(3)234(0)567(-3)g if one wishes, showing simultaneously that this is $\mathbf{1 . 2 3 4 5 6 7}$ $\mathrm{kg}$, or $1234.567 \mathrm{~g}$, or $1234567 \mathrm{mg}$, according to which units are most convenient. In addition, 2(3), meaning 2000 , could be written unambiguousiy as 2 ( 3 with the second bracket understood, again encouraging brevity, and similarly $(6) 14$ ( $=.14$ million) could be written 6) 14.

Of course some problems remain; for example most computers already use brackets in at least two other senses already. Perhaps a convention should be made of using square brackets in computer programs, writing $2[68] 34$ for what is now more clumsily written $2.34 \mathrm{E} 06$ or $2.34 \times 10^{6}$. But these problems should resolve themselves in due course. CEDRIC A.B. SMITH Department of Genetics and Biometry, University College London, UK

\section{Drugs as carcinogens}

SIR - The main impression given by Dr M.

Weatherall (Nature 1 April, p.387) is that the maintenance and improvement of the health of humans should be based principally on the development of new drugs, and that any delay, such as compliance with government regulations, in the introduction of a new drug would result in an increased loss of human health.

Fortunately the approach of regulatory agencies differs from that of the pharmaceutical industries. The agencies attempt to reduce the occurrence in the population of side effects of drugs and to assess the benefits of drug therapy. The causes of the major diseases are only partly known, and an incomplete rationale behind the therapy for such diseases results in what $\mathrm{L}$. Thomas has called "halfway technology"', involving very high costs and relatively unsatisfactory results. An additional problem is that the effectiveness of medicines is oversold ${ }^{2}$.

Improvement of human health in the future will depend on greater knowledge of the aetiopathogenesis of diseases, on improvements in social conditions and on more specific treatments ${ }^{1-7}$. Priority should be given to maintaining a proper balance among these different approaches.

There are certainly limitations in the capacity of in vitro assays and in vivo carcinogenicity tests for the detection of possible carcinogenicity in humans. However, the intelligent use of such tools has proven valid in predicting carcinogenic effects in $\operatorname{man}^{8}$. Of the drugs mentioned by $\mathrm{Dr}$ Weatherall, phenacetin induces tumours of the urinary system of rats, and epidemiological studies ${ }^{9}$ show the same organ system to be the target for its carcinogenic effect in humans; there is also evidence that phenacetin is a mutagen in bacteria and mammalian cells ${ }^{9}$. Azathioprine, chlorambucil and cyclophosphamide, known to be responsible for an increased risk of developing tumours among patients undergoing kidney transplantation, are carcinogenic in experimental animals and mutagenic in various systems ${ }^{9}$. Metronidazole is carcinogenic in mice and rats and mutagenic in bacteria and fungi, while the available epidemiological data are inadequate for a proper assessment of its carcinogenicity in humans. The following drugs or treatments, proven to be carcinogenic in humans, were also found to be carcinogenic in experimental animals: chlornaphazine, myleran, melphalan, methoxsalen (in combination with ultraviolet A irradiation, PUVA), and diethylstilboestrol. Chlornaphazine, myleran, melphalan and PUVA are also mutagens ${ }^{9}$.

Thus evidence of an adverse effect observed in experimental systems should not be underestimated, and in some cases, it can have value as a predictor for a similar effect in humans. This value should increase as more is known of the mechanisms of carcinogenesis.

A summary by Dollery 10 of a recent meeting concludes that there is still a tendency to underestimate risks and to overestimate benefits when evaluating drugs. It seems reasonable that the experimental tests to detect possible side effects of drugs should remain a part of the process of the development of a drug, one of the main aims being the provision of reliable information on which a risk-benefit evaluation can be made. The argument that this process is expensive is tenuous, when one considers that approximately 10 per cent of the budget of the pharmaceutical industry is devoted to research and development and 20 per cent to the marketing of drugs. It is worth mentioning that recently, WHO has listed a total of approximately 200 essential drugs to help in the maintenance of health ${ }^{11}$, a very small number compared with the number of drugs now on the market.

R. Montesano

International Agency for Research on Cancer, Lyon, France

1. Thomas, L. J. med. Educ. 51, $23-29$ (1976).

2. Ingelfinger, F. J. Science 200, 942-946 (1978).

3. Knowles, J. (ed.) Doing Better and Feeling Worse: Health in the United States (Norton, New York, 1977). Mechanic, D. New Engl. J. Med. 298, 249-254 (1978).

5. McKeown, T. The Role of Medicine: Dream, Mirage and Nemesis (Nuffield Provincial Hospitals Trust, London 1976).

6. Saward, E. \& Sorensen, A. Science 200, 889-894 (1978).

7. Lalonde, M. A New Perspective on the Health of Canadians (Ministry of National Health and Welfare, Canadians (Mist

8. Tomatis, L., Breslow, N.E. \& Bartsch, H. in Cancer Epidemiology and Prevention (eds Schottenfeld, D. \& Fraumeni, J.F. Jr) 44-73 (Saunders, Philadelphia, 1982).

9. IARC Monographs on the Evaluation of the Carcinogenic Risk of Chemicals to Humans Suppl.4. (International Agency for Research on Cancer, Lyon, (International Agency for Research on Cancer, Lyon, 10. Dollery, C.T. in Risk-Benefit Analysis in Drug Research (ed. Cavalla,J.F.) (MTP Press, Lancaster, 1981)

11. WHO Tech. Rep. Ser. 635, (1979.

\section{Correction}

THE letter from J. A. Nicoll in Nature of 10 June (p.450) on "Logarithmic SI", contained the following errors. In line 10 $\overline{\mathrm{p}} 2.3$ should read $\mathrm{p} \overline{\mathbf{2}} .3$; in line 25 pDO stands for density, $1 \mathrm{~kg} \mathrm{~m}^{-3}$ not $\mathrm{m}^{-2}$; in line 29 $\overline{\mathrm{p}} \mathrm{L} * 8.5$ should read $\mathrm{pL} * 8.5$; and in line 30 $\mathrm{pL}^{*}$ 9 should read $\overline{\mathrm{p}} \mathrm{L} * 9$. 